\title{
Experimental and Analytical Study of Masonry Infill Reinforced Concrete Frames Retrofitted with Steel Braces
}

\author{
Ricardo Perera , Susana Gómez , and Enrique Alarcón
}

\section{Introduction}

The experimental and numerical research as well as the observations performed in areas affected by earthquakes contribute new data about the seismic behavior of buildings. The advances in this field produce more demanding codes and more effective construction systems. One of the main objectives of seismic engineering is to find simplified methods of assesment of the potential damage in a structure under earthquake loadings as a measure of the repairability of the structure and propose suitable retrofitting strategies.

Within the topic of seismic assessment and retrofitting, special attention has been focused on the seismic behavior of RC frames with masonry infill (Zarnic and Tomasevic 1984; Abrams 1994; Calvi 1996; Madan et al. 1997). In fact, there has been much work conducted on the seismic behavior of infilled frame buildings. The complex nature of the interaction between concrete frames and masonry infill wall panels is reflected in the large number of experimental studies conducted in this area. Although the important effect of infills is recognized, especially in case of seismic actions, in common design practice their presence is ignored and this simplification may in some cases result in unsafe structures, especially in those buildings designed with obsolete codes or even without taking into account any seismic specification.
This paper is focused on the experimental and numerical evaluation of a retrofitting strategy applied to RC buildings with masonry infill walls designed with old codes in which seismic provisions are unsufficiently considered. In the proposed scheme selected infill panels of a building are replaced with K-bracing with vertical shear link (Fig. 1). With this approach the stiffening effect provided by the masonry is kept while its low ductility is compensated with the energy dissipation capacity of the link element. These additional steel elements transfer the lateral loads from the floors to the diagonal bracing.

Usually, the shear links are located horizontally either at the middle or at the ends of the floor beams. In the case of severe earthquakes, large deformations of the shear links in those beams have to be accepted. However, using vertical shear links the region of plastic deformations is transferred to locations where postearthquake repair is easier. As a result, a seismic resistant structural frame system by vertical shear link in an eccentrically braced frame (V-EBF) is obtained. If the link element is welldesigned, the inelastic action of the system is confined to the link element. Therefore the strength and ductility of the frame are directly related to the strength and ductility of the shear link.

In parallel with the experimental results obtained for this retrofitting scheme, a numerical damage model has been developed with the purpose of performing numerical evaluations about seismic behavior of this type of RC structures and on proposed solutions of retrofitting. The proposed model for frame and masonry elements is based on notions and principles of continuum damage mechanics and, therefore, on thermodynamics of irreversible processes. Therefore the models include explicitly the coupling between damage and mechanical behavior and are consistent with the definition of damage as a phenomenon with mechanical consequences. The numerical model, implemented in a computer code for a nonlinear response analysis in two dimensions, is used in the simulation of the retrofitting scheme presented above.

In the following, the numerical model is presented first. Then, the experimental results of a RC frame with masonry infill panels retrofitted according to the strategy proposed above are shown. Finally, before the conclusions, a comparison between experimental and numerical results is performed. 


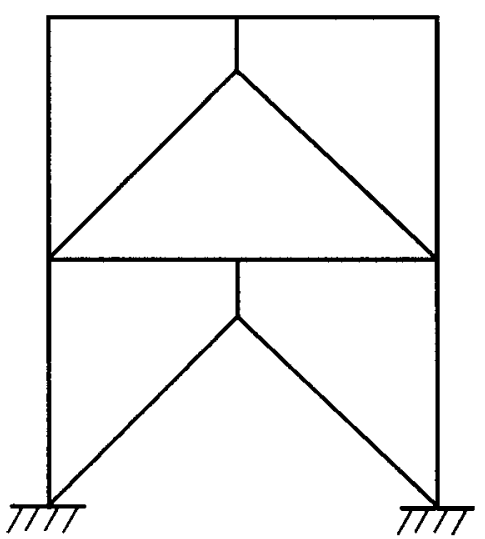

Fig. 1. Vertical shear link in eccentrically braced frame

\section{Numerical Model}

For the numerical evaluation of structural damage in RC frames with masonry infill panels and the subsequent simulation of the retrofitting technique proposed in this work, three different numerical models have been developed, two damage models for both frame elements and masonry infill panels and, finally, the model representing the shear-link element. A brief description of these models is provided below.

\section{Lumped Damage Model for Beam/Column Elements}

Damage models based on continuum damage mechanics produce too many complex formulations. To avoid this, a simplified approach based on the application of the concepts of continuum damage mechanics to lumped dissipative models is used in this study. These models correspond to a generalization of the lumped plasticity models (Cohn and Franchie 1979) in order to include the dissipative effects produced by structural damage.

With the lumped damage model each member of the RC frame is represented as an assemblage of an elastic beam-column, flexural springs at the ends of the element and an axial spring. In this way, dissipative deformations (plastic and damage deformations) are lumped at its two ends. This model, adding the damage effect, is consistent with the traditional assumptions of plastic hinge (plastic rotation) and bar hinge (axial deformation). The stress distribution for each element is described by a three component vector $[q]^{t}=\left(M_{i} M_{j} N\right)$ that collects the bending moments at the two ends, $M_{i}$ and $M_{j}$, and the axial force, $N$. The corresponding kinematic variable $[u]^{t}=\left(\theta_{i} \theta_{j} \delta\right)$ defines the deformed shape of the element excluding the rigid body motion.

For the axial spring, using the effective stress concept and the strain equivalence principle (Lemaitre 1996), the following constitutive relation is obtained:

$$
\delta_{b}^{d}=\frac{N_{b} L_{b}}{E A} \frac{d_{a}}{\left(1-d_{a}\right)}
$$

where $N_{b}$ and $L_{b}=$ axial foree and the length of the element, respectively, and in which $\delta_{b}^{d}$ and $d_{a}$ are the elongation due to damage and the axial damage, respectively.

The strength-deformation relationship of flexural springs is expressed as moment versus rotation taking into account the effect of flexural damage. From Eq. (1), a similar relationship is postulated for flexural effects

$$
\begin{aligned}
& \theta_{i}^{d}=\frac{d_{i}}{1-d_{i}} \frac{L_{b}}{4 E I} M_{i} \\
& \theta_{j}^{d}=\frac{d_{j}}{1-d_{j}} \frac{L_{b}}{4 E I} M_{j}
\end{aligned}
$$

$\theta_{i}^{d}$ and $\theta_{j}^{d}=$ damage rotations at the ends of the element and $d_{i}$ and $d_{j}=$ damage variables due to flexural effects associated to each end of the member.

Eqs. (1) $-(3)$ define the flexibility matrix $\left[F^{d}\right]$ of the hinges due to damage:

$$
\left[F^{d}\right]=\left(\begin{array}{ccc}
\frac{d_{i}}{\left(1-d_{i}\right)} \frac{L_{b}}{4 E I} & 0 & 0 \\
0 & \frac{d_{i}}{\left(1-d_{i}\right)} \frac{L_{b}}{4 E I} & 0 \\
0 & 0 & \frac{d_{a}}{\left(1-d_{a}\right)} \frac{L_{b}}{E A}
\end{array}\right)
$$

Considering damage and plastic deformations, the constitutive law is given by

$$
[u]-\left\lfloor u^{p}\right\rfloor=\left\lfloor u^{b}\right\rfloor+\left\lfloor u^{d}\right\rfloor=\left(\left\lfloor F^{o}\right\rfloor+\left\lfloor F^{d}\right\rfloor\right)[q]
$$

where $\left\lfloor u^{b}\right\rfloor,\left\lfloor u^{p}\right\rfloor$, and $\left\lfloor u^{d}\right\rfloor$ represent the elastic, plastic, and damage deformations, respectively, and $\left\lfloor F^{\circ}\right\rfloor$ the corresponding elastic flexibility matrix.

The evolution of damage and plastic variables is formulated through a damage potential, $\varphi_{d}$, and a plastic potential, $\varphi_{p}$, within the framework of thermodynamics of irreversible processes. Plastic and damage potentials associated to the beam/column elements are defined such as they are displayed in Perera et al. (2000)

In the case of hysteretic behavior, two different sets of damage variables are defined, one for positive actions and the other for negative actions, and a unilateral behavior is assumed, i.e., damage due to positive actions has no influence on the behavior of the member under negative actions and vice versa (Flórez-López 1995). More details about the modeling of the beam-column element can be found in Perera et al. (2000).

\section{Damage Model for Masonry Infill Panels}

The model developed here for masonry infill panels is based on a simplified or global approach. For it, the contribution of the masonry infill panel to the response of the infilled frame is modeled by a system of two diagonal masonry compression struts (Calvi 1996). Since the tensile strength of masonry is negligible, the individual masonry struts are considered to be ineffective in tension. The combination of both diagonal struts provides the lateral load resisting mechanism for the opposite lateral directions of loading.

Each strut element is modeled as a simple longitudinal inelastic spring loaded axially whose behavior is described in terms of the axial force-axial deformation relation of the strut using the notions and principles of continuum damage mechanics through the effective stress concept and the strain equivalence principle such as it was displayed above for the beam/column elements. The following relation is obtained:

$$
N=K_{0}(1-d) \delta^{e}=K_{0}(1-d)\left(\delta-\delta^{p}\right)
$$

where $N=$ axial force of the strut, $\delta, \delta^{e}$, and $\delta^{p}=$ total, elastic, and plastic shortenings of the strut, respectively, $K_{0}=$ initial stiffness 
prior to cracking, and $d=$ internal damage variable representing the degradation of the infill.

Damage index, $d$, can be considered as a measure of the progressive decrease of the effective width of the diagonal compression strut, due to the cracking occurring in the infill panel by tension effects.

Many alternative approaches have been proposed in the literature to estimate the initial stiffness $K_{0}$. The underlying concept employed to calculate this parameter is based on the approach used to determine the equivalent strut width. In this study, the approach proposed by Mainstone (1971) has been used.

The estimation of the damage and plastic elongation evolution laws in Eq. (6) is performed according to the thermodynamics of irreversible processes.

To define the plastic strain evolution law, assuming positive values for compressive forces and shortenings, the following plastic potential is proposed (Gómez 2000)

$$
f=N-\left[A_{1} e^{-B_{1} \delta^{p}}+A_{2} e^{-B_{2} \delta^{p}}\right]
$$

$A_{1}, B_{1}, A_{2}$, and $B_{2}=$ four constants of unknown value. This potential represents the strength envelope of the equivalent strut and its shape is controlled through the four previous constants. To obtain the value of the four unknown constants appearing in Eq. (7), the following conditions in monotonic loading are used:

$$
\begin{gathered}
\frac{d N}{d \delta^{p}}=K_{0} \text { implies } \delta^{p}=0 \text { and } f=0 \\
N=N_{y} \text { implies } \delta^{p}=0 \text { and } f=0 \\
\frac{d N}{d \delta^{p}}=0 \text { implies } \delta^{p}=\delta_{u}^{p} \text { and } f=0 \\
N=N_{u} \text { implies } \delta^{p}=\delta_{u}^{p} \text { and } f=0
\end{gathered}
$$

where $N_{y}=$ yielding axial force; $N_{u}=$ ultimate axial force; and $\delta_{u}^{p}=$ plastic shortening that corresponds to the ultimate axial force. The first condition is justified by experimental tests. According to those, a slight change in lateral stiffness appears with the first minor cracks and at the first separation of the infill from the surrounding frame. However, since this early change in stiffness is relatively minor, it is not included in the model.

The three parameters, $N_{y}, N_{u}$, and $\delta_{u}^{p}$, can be identified by calibrating the monotonic loading curve to the corresponding results obtained through the refined simulation or experimental tests of the response of the infilled frames subjected to monotonically increasing lateral displacements. In fact, some approaches have been proposed in the literature (Zarnic and Tomasevic 1984; Pires and Carvalho 1992).

For the damage evolution law, it is assumed in the model that damage is associated to the plastification; because of it, the damage evolution is defined through the energy dissipated by the element by plastification. The following expression has been proposed:

$$
d=\frac{E\left(\delta^{p}\right)}{E_{\infty}}
$$

where

$$
E\left(\delta^{p}\right)=\int_{0}^{\delta^{p}} N\left(\delta^{p}\right) d \delta^{p}
$$

is the energy dissipated by the element and

$$
E_{\infty}=\int_{0}^{\infty} N\left(\delta^{p}\right) d \delta^{p}
$$

is the value of the maximum dissipated energy which corresponds to the fracture. Due to the difficulty of determining $E_{\infty}$, the following theoretical value has been obtained from $E\left(\delta^{p}\right)$ when $\delta^{p}$ approaches to $\infty$ using the axial force as defined in Eq. (7):

$$
E_{\infty}=\frac{A_{1}}{B_{1}}+\frac{A_{2}}{B_{2}}
$$

Combining Eqs. (6), (7), and (9), the plastic shortening can be obtained by means of a Newton-Raphson iterative procedure and then damage is defined from Eq. (9).

\section{Vertical Shear-Link-Element Model}

In the proposed retrofitting technique one of the infill panels was replaced by a vertical shear link in an eccentrically braced frame (V-EBF). As it can be observed in Fig. 1, the vertical shear link is located at the midspan underneath the floor beams and connected to a chevron bracing.

The vertical shear-link model used in this study is based on the approach proposed by Ricles and Popov (1987a) for horizontal shear-link elements considering for its formulation the experimental results obtained at the Institute of Steel Construction at TU-Darmstadt (Germany) on vertical elements (Tamijani 1998).

According to the Ricles and Popov's approach (1987a) the shear-link element is modeled as a linear beam element with three nonlinear hinges at the ends where all inelastic actions are assumed to be concentrated in the form of a shear force and a moment. Assuming a bilinear force-deformation relationship for
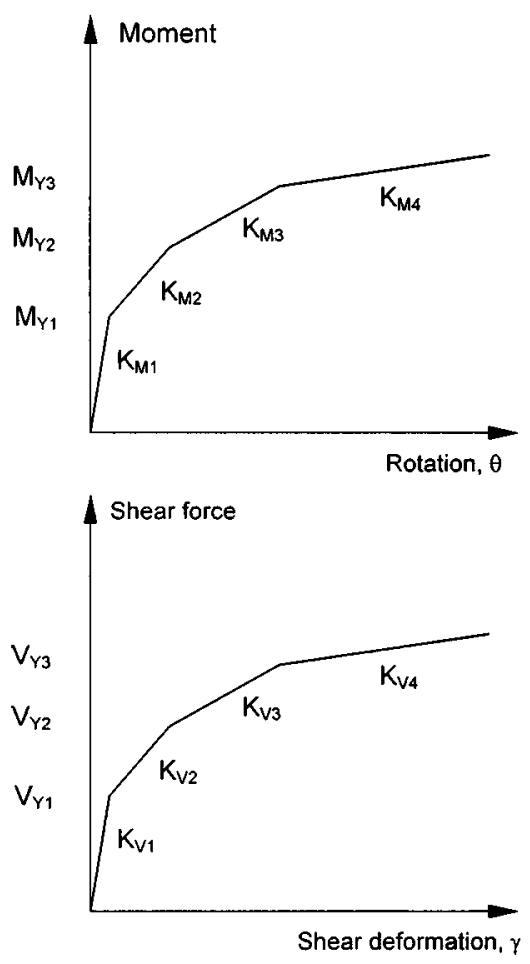

Fig. 2. Multilinear hardening behavior for bending moment-rotation and shear force-deformation relationships 
each hinge, the combination in parallel at the ends of the element results in a multilinear relationship for the shear and the moment (Fig. 2).

Experimental evidence (Kasai and Popov 1986; Ricles and Popov 1987b) suggests that isotropic hardening is more suitable in shear yielding while kinematic hardening is assumed for moment yielding. In the same way, for shear yielding an upper bound of shear $V_{\max }$ is adopted after complete hardening.

The definition of the model requires the determination of the parameters governing the multilinear shear force-deformation and bending moment-rotation relationships (Fig. 2). From experimental results performed at ELSA laboratory (Ispra, Italy) and Darmstadt University on vertical shear links the following calibrations for the analytical model of these shear-link elements have been adopted:

1. For shear ( $V$ values) and moment ( $M$ values)

$$
\begin{array}{ll}
V_{Y 1}=1.0 V_{Y} & M_{Y 1}=1.00 M_{Y} \\
V_{Y 2}=1.5 V_{Y} & M_{Y 2}=1.03 M_{Y} \\
V_{Y 3}=2.0 V_{Y} & M_{Y 3}=1.06 M_{Y}
\end{array}
$$

$V_{Y}$ and $M_{Y}=$ values of the shearing force and the moment at initial yield, respectively.

2. For shear ( $K_{V}$ values) and moment ( $K_{M}$ values)

$$
\begin{array}{ll}
K_{V 2}=0.100 K_{V 1} & K_{M 2}=0.030 K_{M 1} \\
K_{V 3}=0.030 K_{V 1} & K_{M 3}=0.015 K_{M 1} \\
K_{V 4}=0.007 K_{V 1} & K_{M 4}=0.002 K_{M 1}
\end{array}
$$

where $K_{V 1}=6 E I / e ; K_{M 1}=G A_{\mathrm{web}} / e ; \quad e=$ link length; and $A_{\text {web }}=$ area of the web of the link section.

\section{Experimental Analysis}

\section{Test Specimen and Material Properties}

To test the proposed retrofitting scheme, experimental tests were performed at ELSA laboratory on a full-scale four story RC bare frame system with three bays, two with $5 \mathrm{~m}$ span and one with 2.5 $\mathrm{m}$ span. Interstory height is $2.7 \mathrm{~m}$. This concrete frame was designed essentially only for gravity loads and the reinforcement
Table 1. Material Properties of Infilled Frame

\begin{tabular}{llc}
\hline Material & \multicolumn{1}{c}{ Properties } & Value \\
\hline Steel & Young modulus (MPa) & $200,000.0$ \\
& Yield strength (MPa) & 337.0 \\
& Ultimate strength (MPa) & 455.0 \\
& Strain at maximum load & $25.0 \%$ \\
Concrete & Young modulus (MPa) & $20,000.0$ \\
& Compressive strength (MPa) & 24.0 \\
Brick masonry & $\begin{array}{l}\text { Tensile strength (MPa) } \\
\text { Strength parallel to the holes }\end{array}$ & 1.9 \\
& (bricks) (MPa) & 15.4 \\
& $\begin{array}{l}\text { Strength perpendicular to the } \\
\text { holes (bricks) (MPa) }\end{array}$ & 2.8 \\
& $\begin{array}{l}\text { Young modulus parallel to the } \\
\text { holes (wallete) (MPa) }\end{array}$ & 991.0 \\
& $\begin{array}{l}\text { Compressive strength parallel to } \\
\text { the holes (wallete) (MPa) }\end{array}$ & 1.1 \\
& $\begin{array}{l}\text { Young modulus perpendicular to } \\
\text { the holes (wallete) (MPa) } \\
\text { Compressive strength perpendicular }\end{array}$ & $1,873.0$ \\
& to the holes (wallete) (MPa) & 1.1 \\
\hline
\end{tabular}

details were specified to be representative of buildings constructed over 40 years ago in European Mediterranean countries. Material properties of the beam/column elements are shown in Table 1. Before performing the retrofitting, the bare frame was tested pseudodynamically.

The proposed technique of retrofitting was tested only on the second floor of the frame and for it two walls and a vertical shear link in an eccentrically braced frame (V-EBF) were introduced in this floor such as it is represented in Fig. 3. The vertical shear link is located at the midspan underneath the floor beams and connected to a chevron bracing. The walls were constructed in order to study the influence of the V-EBF on frames with masonry infill panels. With this technique the stiffening effect introduced by the masonry walls is kept while their low ductility is compensated by the excellent energy-disipating behavior of the shear link.

For the link specimen a HE120A section was adopted. In designing the vertical shear link a shear strength, $V_{Y}$, similar to the foreseen value of the masonry walls was used with the purpose of not increasing the strength of the structure significantly and, therefore, overloading the foundation. This element with large stiffness and low yield displacement results is effective in protect-
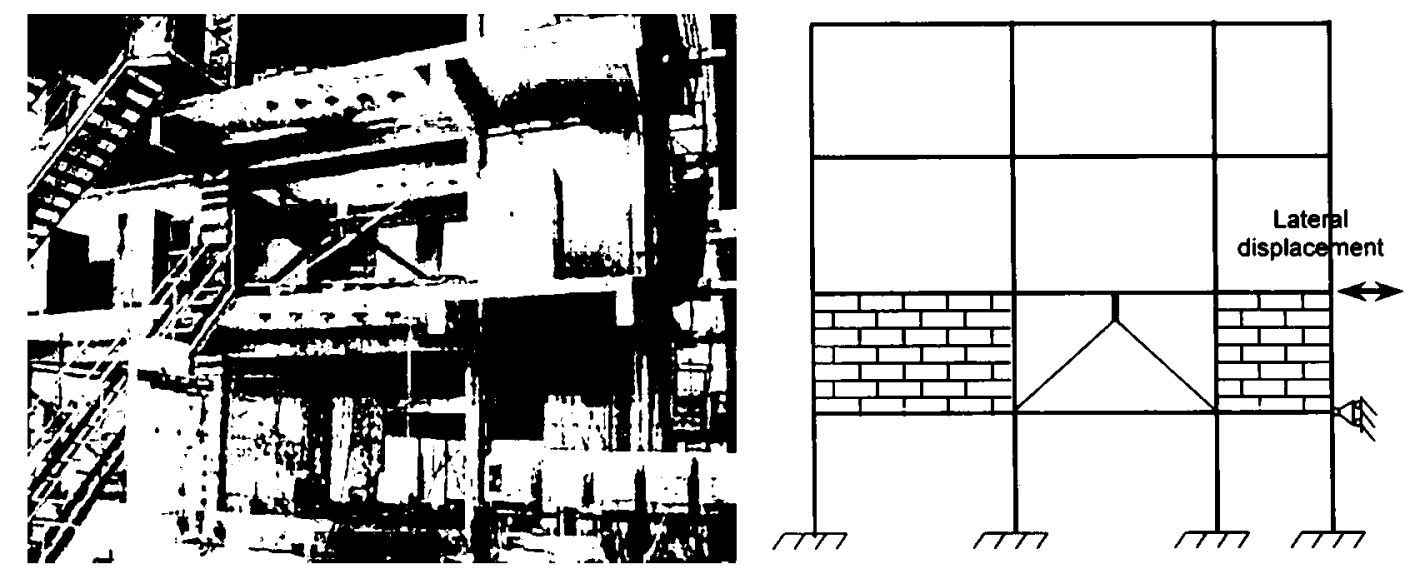

Fig. 3. Retrofitting scheme with vertical shear link and loading condition of the test setup 
Table 2. Characteristics of Vertical Shear Link

\begin{tabular}{lc}
\hline Characteristics & Values \\
\hline Yielding stress (flanges) & $360.0 \mathrm{E}-6 \mathrm{~N} / \mathrm{m}^{2}$ \\
Yielding stress (web) & $380.0 \mathrm{E}-6 \mathrm{~N} / \mathrm{m}^{2}$ \\
$V_{y}$ & $118.6 \mathrm{kN}$ \\
$V_{\max }$ & $250.0 \quad \mathrm{kN}$ \\
$M_{y}$ & $20.2 \quad \mathrm{kN} \mathrm{m}$ \\
\hline
\end{tabular}

ing structures of limited deformation capacity. More details about the design can be found in Tamijani (1998). The main characteristics of the vertical shear link are given in Table 2 and details of the used sections in V-EBF are shown in Fig. 4. For the walls, $0.245 \times 0.115 \times 0.245 \mathrm{~m}$ bricks horizontally perforated with $50-60 \%$ voids were used. The average compressive strength of masonry perpendicular and parallel to the hollows are given in Table 1.

\section{Test Setup and Load History}

The reversing lateral forces were applied by servohydraulic actuators mounted on a reaction wall. The columns were instrumented to monitor the applied displacements and loads were measured by load cells. Inclinometers were located at the columns to measure the plastic hinge rotations at critical sections of the columns and displacement transducers were installed to measure the interstory drift and the deformations of the walls. The relative displacement between the ends of the vertical shear link was also measured using displacement transducers.

For testing the retrofitted story, the second story was subjected to cyclic lateral load in displacement control restricting the displacement at the first story. The cycling displacement history was chosen from the monotonic behavior expected for the retrofitted story through some previous numerical studies and is shown in Table 3. The specimen was subjected to three fully reversed displacement cycles at each amplitude level in order to take into account also the repetitive effect

\section{Experimental Results}

From the test, the force-displacement relationship for the second floor shown in Fig. 5 was obtained. Three different stages appear through the observation of this relationship. In the first cycles, the stiffness and the strength do not experiment important variations and the shear link has not yielded still. The nonlinear effects are due to the masonry walls and the damaged initial stage of the frame. In this first stage, the lateral displacement corresponds to $0.00432 \mathrm{~m}$.

In the following three displacement levels the nonlinearity is evident. When lateral displacement reaches $0.00648 \mathrm{~m}$ yielding of

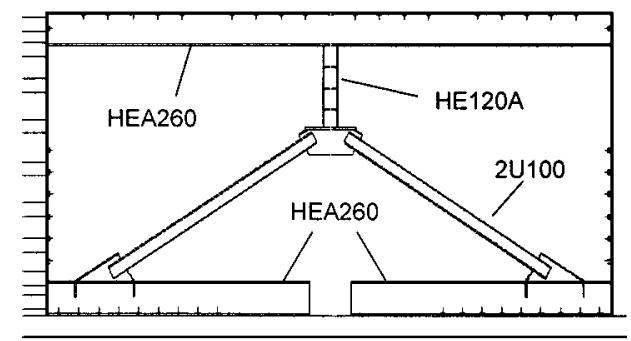

Fig. 4. Used sections in V-EBF
Table 3. Loading History

\begin{tabular}{lc}
\hline $\begin{array}{l}\text { Interstorey drift } \\
(\%)\end{array}$ & Displacement $(\mathrm{m})$ \\
\hline 0.04 & 0.00108 \\
0.08 & 0.00216 \\
0.12 & 0.00324 \\
0.16 & 0.00432 \\
0.24 & 0.00648 \\
0.32 & 0.00864 \\
0.48 & 0.01296 \\
0.64 & 0.01728 \\
0.80 & 0.02160 \\
\hline
\end{tabular}

the shear link occurs. Loss of lateral adherence between the frame and the walls as well as cracking and crushing in the wall corners is also observed

In the last cycles of the second stage $(0.01296 \mathrm{~m})$ an evident decrease of strength is produced due to the loss of shear strength in the exterior columns. Bending yielding of the flanges of the shear link is developed also and the crushing of the walls follows.

In the last cycles, shear failure occurred in the exterior columns while the shear-link element had still not reached the maximum capacity as it can be observed in the shear forcedisplacement curve corresponding to the shear-link element in Fig. 6. Shear force of the shear-link element was determined by equilibrium from the axial forces of the diagonal bracing. A large amount of the energy was dissipated by the inelastic shear strain of the vertical shear-link element.

It is important to say that during the last cycles of the test $(0.01728 \mathrm{~m})$, the part of the walls contacting the exterior columns was eliminated. This was done with the purpose of reaching a higher lateral displacement $(0.02160 \mathrm{~m})$. From the results, it can be said that the retrofit was successful since an acceptable level of ductility was reached and, moreover, the maximum capacity of the shear-link element was not reached during the test.

\section{Analytical Simulation}

The proposed models for beam/column elements, masonry infill panels, and vertical shear-link elements in previous sections were

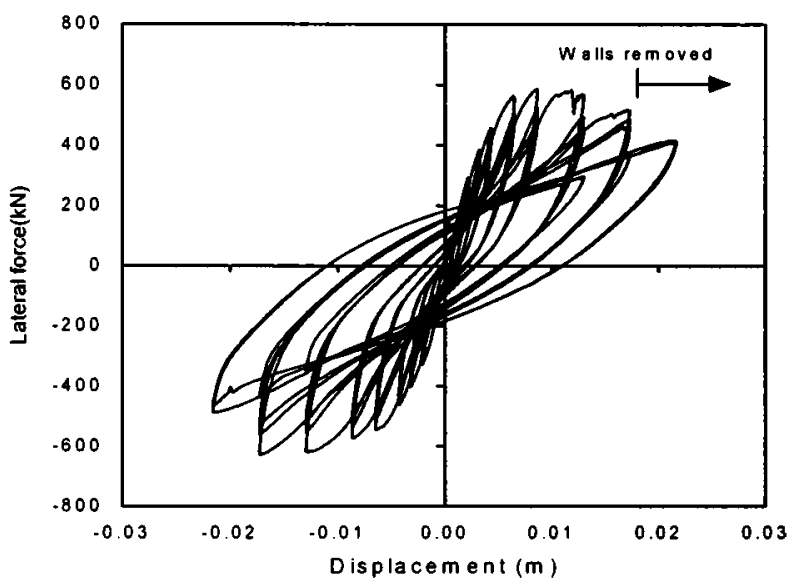

Fig. 5. Experimental behavior for the retrofitted story with V-shear link 


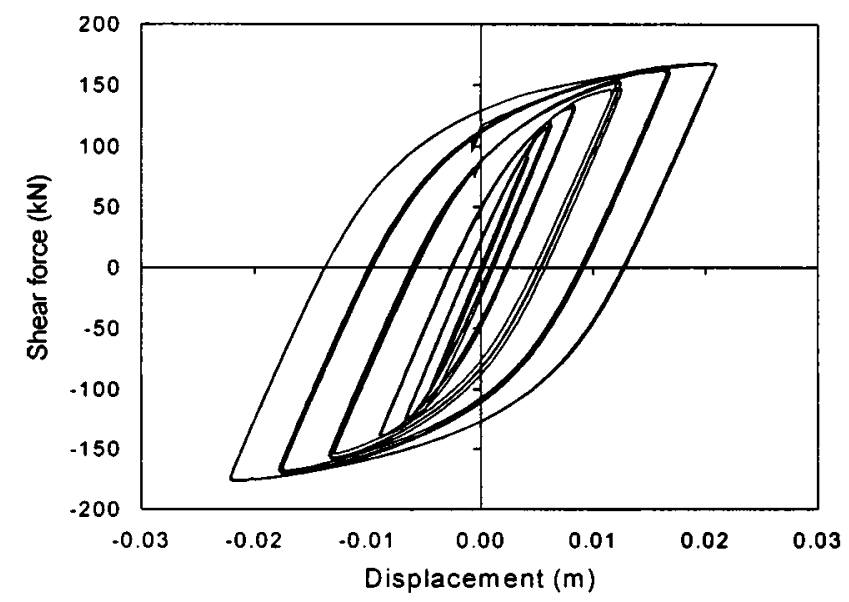

Fig. 6. Shear force-displacement curve of the vertical shear link (experimental)

implemented in a computer program for the two-dimensional inelastic analysis and damage evaluations of RC buildings under combined dynamic, static, and quasistatic loading. Previous to the numerical simulation of the experimental test, the damage models were calibrated by comparison with experimental results from the literature.

\section{Calibration of Damage Models}

To evaluate the proposed damage models, the experimental results obtained by Mehrabi et al. (1996) on masonry-infilled RC frames were taken. From all tested specimens and numerically simulated, the fifth specimen is presented here for comparison. This specimen had a weak frame and a strong panel constituted by solid masonry units and it was subjected to a fully reversed displacement cycle and, moreover, the failure mode of the panel coincides with that observed for the panels of the tested retrofitted frame.

The parameters of the numerical damage models were estimated from the material tests on concrete and masonry. For the masonry, results from compression tests of three-course masonry prisms were adopted. In Fig. 7, the numerical and experimental load-displacement curves are shown. As it can be observed, a good estimation of the strength has been reached with the numerical model. In the same way, the stiffness degradation is perfectly represented by the model. To check this, in Fig. 8 the damage

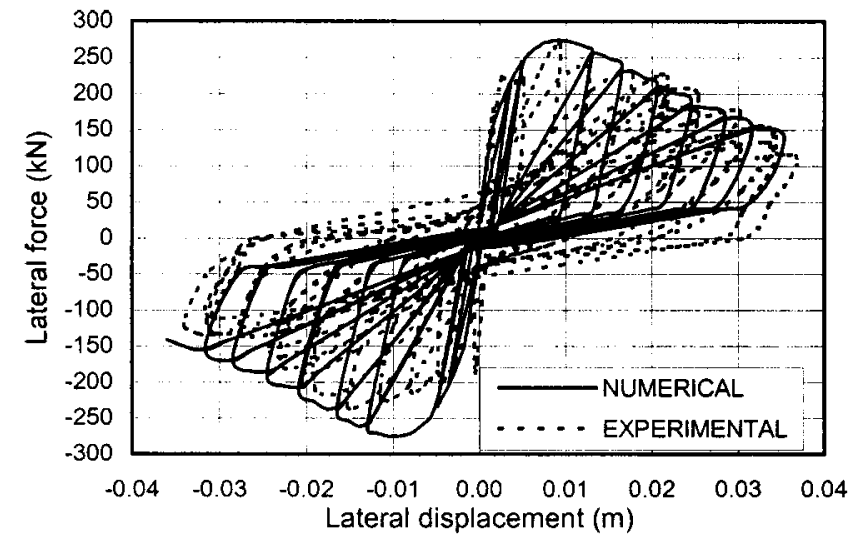

Fig. 7. Experimental and numerical curves for specimen 5

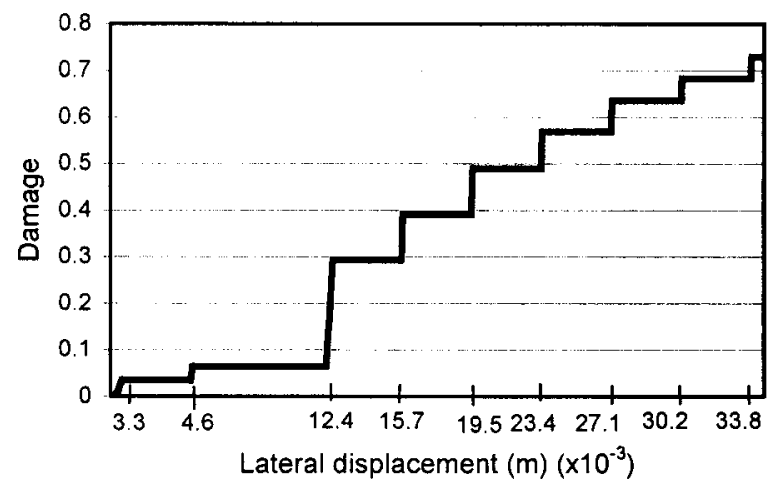

Fig. 8. Numerical damage evolution of the diagonal strut for specimen 5

evolution for one of the diagonal struts is shown. According to the experimental tests the sliding cracks in the infills were first observed at the maximum lateral loads. For that level, numerical damage reaches a value less than 0.1 which is also insignificant; it corresponds to the crack initiation. As the amplitude of displacement cycles increased, crushing developed in the infill. The initiation of crushing is reflected in the numerical model since damage experiments jump from 0.07 to 0.3 . As crushing spreads numerical damage increases progressively to reach finally a value of 0.73 . In general, damage values higher than 0.5 can be considered to correspond to heavy damage. From this comparison, it can be stated that the correlation between the calculated damage and the physical observations is good.

\section{Numerical Simulation of Experimental Results}

With the proposed numerical models, a static cyclic inelastic analysis was performed on the retrofitted frame described above and results were compared with the test results. For the calculations, the entire test frame was modeled. The structural model used for the analysis of the test frame is shown in Fig. 9. The first story was restricted against lateral displacement while the second story was subjeted to the cyclic displacement history. The beam/ column parameters necessary for the model were defined according to the properties of the RC cross sections. For the diagonal strut model, representing the masonry walls, the model parameters were obtained through a previous refined simulation of the wall using finite elements. For the diagonal braces elastic beam elements were assumed.

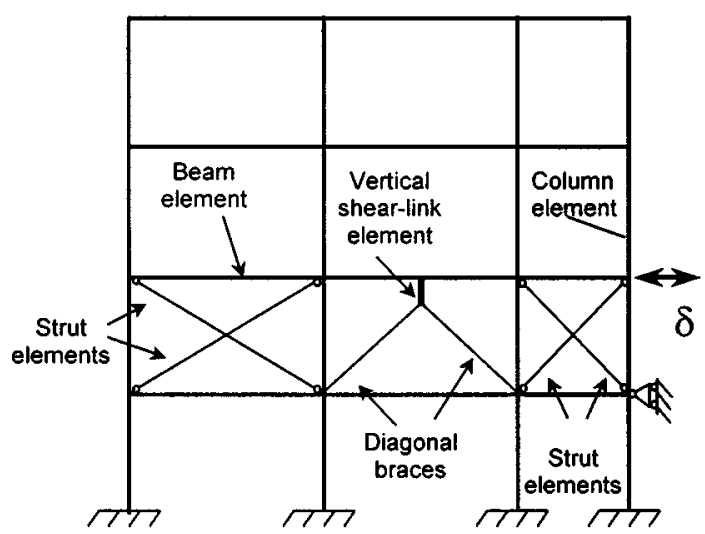

Fig. 9. Proposed structural model for the retrofitted test frame 


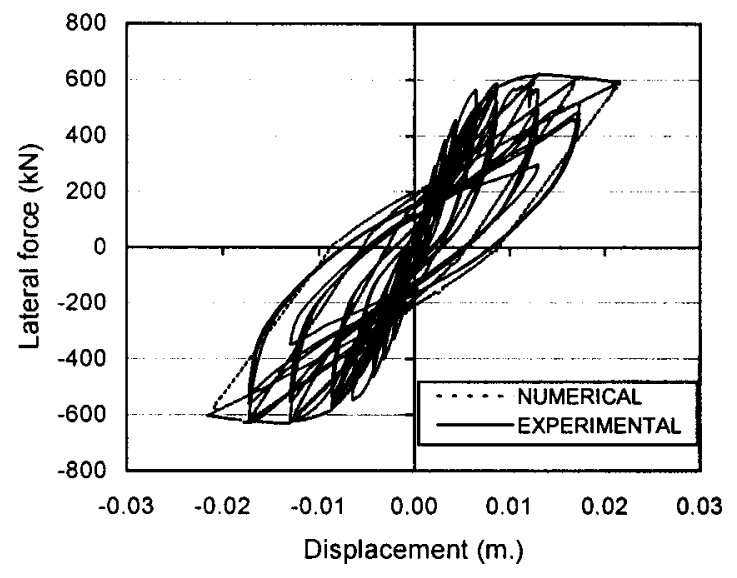

Fig. 10. Experimental versus numerical results for the retrofitted floor with V-shear link

The same loading history shown in Table 3 is applied on the second floor. In Fig. 10 the numerical and experimental results are shown. In general terms, a good correlation between numerical and experimental results in the global behavior of the floor has been obtained. As it can be observed from numerical results, the maximum strength reached by the retrofitted frame is perfectly predicted by the numerical model.

However, some phenomena were not represented by the model. For example, the strength degradation of the last cycles does not appear in the numerical results and, therefore, it is not shown in Fig. 10. This is due to the fact that in the last cycles the part of the walls contacting with the columns was eliminated and that phenomenon was not simulated by the model. Moreover, the strength degradation due to cumulative effects is not represented either by the model.

Another difference exists also between experimental and numerical results in the representation of the initial stiffness. Its value is lower in the numerical model since the initial stage of cracking and progressive separation between the frame and the walls are not represented by the model.

In Fig. 11, the numerical damage distribution is shown for the retrofitted floor when the ultimate load is reached. Higher values than 0.5 (heavy damage) appear in the masonry struts which is consistent with the experimental test since crushing of the walls was reached. In the same way, high damage values are reached at the exterior columns.

The curve of shear force versus displacement for the vertical shear link obtained numerically is shown in Fig. 12 in comparison with the experimental curve. A good agreement in the maximum values is also reached comparing both of them.

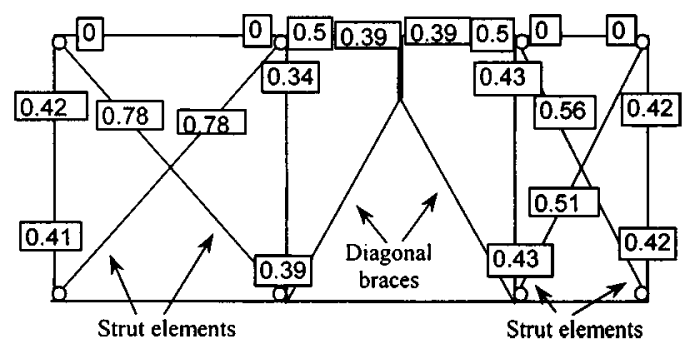

Fig. 11. Numerical damage distribution for the retrofitted floor

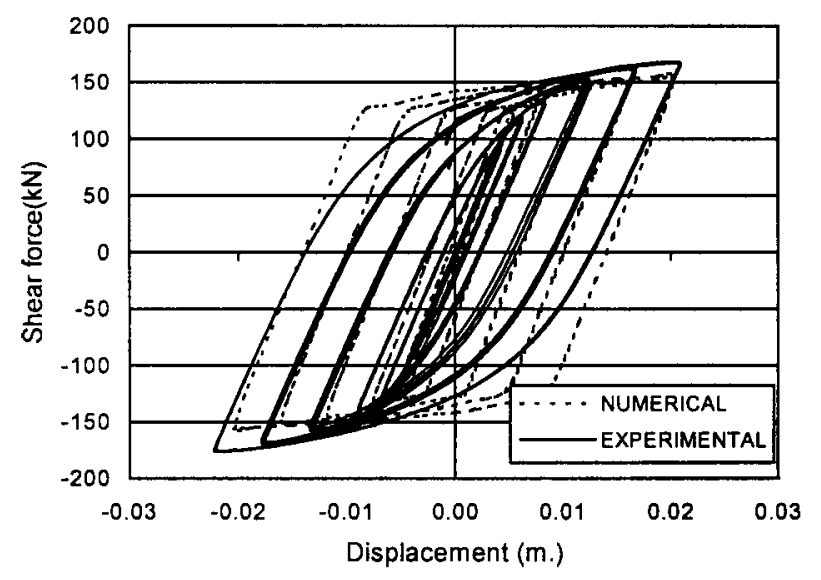

Fig. 12. Numerical and experimental shear force-displacement curves of the vertical shear link

\section{Conclusions}

An experimental study of the behavior of $\mathrm{RC}$ frames with masonry infill panels retrofitted by means of eccentric braces with vertical shear link has been presented. The use of these vertical elements has shown an excellent energy dissipation capacity and the results are particularly attractive as it allows designing such elements only for horizontal shear forces such as earthquake induced forces.

A numerical model to simulate the behavior of the proposed retrofitting strategy has been developed. For the RC beam/column elements and for the masonry panels a simplified damage model has been used. For the vertical shear-link element the same approach employed usually for simulating the behavior of horizontal shear-link elements has been used. The parameters of the model have been defined through experimental tests on vertical shear links. The numerical model has been verified and used to simulate the behavior of the eccentrically braced masonry infill $\mathrm{RC}$ frame tested under displacement controlled cyclic loading as shown in this paper.

Reasonably good agreement between experimental measurements and analytical results has been observed for the global behavior of the retrofitted frame. The shear force developed on the vertical shear link has been also predicted reasonably well by the numerical model. These results show the reliability of using the proposed model for inelastic cyclic analysis of eccentrically braced masonry infill RC frames. Moreover, the estimated numerical damage values for the beam/column elements and for the masonry panels are in good agreement with the physical damage observed during the tests with which it can be stated that the proposed model is suitable to estimate the damage distribution of this kind of structures and, therefore, as a means of predicting the safety of a structure.

\section{Acknowledgments}

The experimental data used in this paper were obtained from the testing campaign at the ELSA Laboratory of the JRC and financed by the European Commission under the Training and Mobility of Researchers programme, namely the TMR-Large-scale facilities and the ICONS TMR-Network. 


\section{Notation}

The following symbols are used in this paper:

$A=$ section area;

$A_{\text {web }}=$ web area of link section;

$A_{1}, A_{2}=$ constants appearing in the plastic potential for the strut element;

$B_{1}, B_{2}=$ constants appearing in the plastic potential for the strut element;

$d=$ damage of the infill;

$d_{a}=$ axial damage of a beam/column element;

$d_{i}, d_{j}=$ beam/column element end flexural damages;

$E=$ Young's modulus;

$E\left(\delta^{p}\right)=$ energy dissipated by the strut element;

$E_{\infty}=$ maximum dissipated energy by the strut element;

$e=$ link length;

$\left[F^{d}\right]=$ damage flexibility matrix;

$\left[F^{\circ}\right]=$ elastic flexibility matrix;

$f=$ plastic potential for the strut element;

$G=$ shear modulus;

$I=$ moment of inertia;

$K_{M 1}, K_{M 2}, K_{M 3}, K_{M 4}$

$=$ moment stiffnesses of the link element;

$K_{0}=$ initial stiffness of infill;

$K_{V 1}, K_{V 2}, K_{V 3}, K_{V 4}$

$=$ shear stiffnesses of the link element;

$L_{b}=$ length of beam/column elements;

$M_{i}, M_{j}=$ element end moments;

$M_{Y}=$ moment at initial yield of the link element;

$M_{Y 1}, M_{Y 2}, M_{Y 3}$

$=$ yielding moment values of the link element;

$N=$ axial force of the strut;

$N_{b}=$ axial force of the beam/column element;

$N_{u}=$ ultimate axial force of the strut;

$N_{y}=$ yielding axial force of the strut;

$[q]=$ generalized stresses vector of a beam/column element;

$[u]=$ generalized deformations vector of a beam/ column element:

$\left[u^{b}\right],\left[u^{d}\right],\left[u^{p}\right]$

$=$ generalized elastic, damage, and plastic deformations vector of a beam/column element;

$V_{\max }=$ maximum shear force of the link element;

$V_{Y}=$ shear force at initial yield of the link element; $V_{Y 1}, V_{Y 2}, V_{Y 3}$

$=$ yielding shear values of the link element;

$\delta=$ total shortening of the strut;

$\delta_{b}^{d}=$ damage elongation of a beam/column element;

$\delta^{e}, \delta^{p}=$ elastic and plastic shortening of the strut;

$\delta_{u}^{p}=$ ultimate plastic shortening of the strut;

$\theta_{i}, \theta_{j}=$ element end total rotations;

$\theta_{i}^{d}, \theta_{j}^{d}=$ element end damage rotations; $\varphi_{d}=$ damage potential of a beam/column element; and

$\varphi_{p}=$ plastic potential of a beam/column element. 